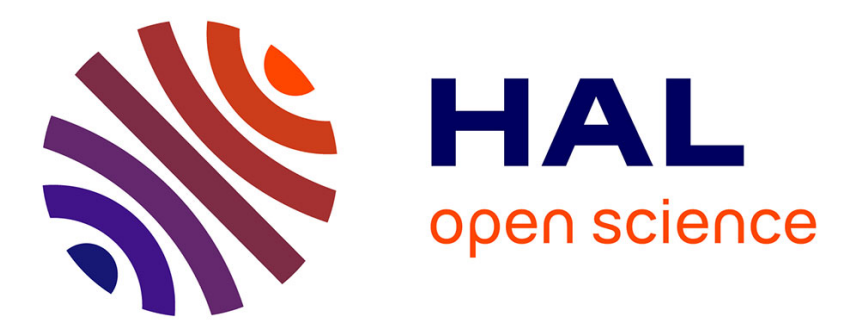

\title{
Collaborative and Sustainable Network Design in Courier Services
}

\author{
Ki Ho Chung, Seung Yoon Ko, Chang Seong Ko
}

\section{To cite this version:}

Ki Ho Chung, Seung Yoon Ko, Chang Seong Ko. Collaborative and Sustainable Network Design in Courier Services. IFIP International Conference on Advances in Production Management Systems (APMS), Aug 2018, Seoul, South Korea. pp.254-261, 10.1007/978-3-319-99704-9_31 . hal-02164893

\section{HAL Id: hal-02164893 \\ https://hal.inria.fr/hal-02164893}

Submitted on 25 Jun 2019

HAL is a multi-disciplinary open access archive for the deposit and dissemination of scientific research documents, whether they are published or not. The documents may come from teaching and research institutions in France or abroad, or from public or private research centers.
L'archive ouverte pluridisciplinaire HAL, est destinée au dépôt et à la diffusion de documents scientifiques de niveau recherche, publiés ou non, émanant des établissements d'enseignement et de recherche français ou étrangers, des laboratoires publics ou privés.

\section{(c)(1)}

Distributed under a Creative Commons Attribution| 4.0 International License 


\title{
Collaborative and Sustainable Network Design in Courier Services
}

\author{
Ki Ho Chung ${ }^{1}$, Seung Yoon $\mathrm{Ko}^{2}$ and Chang Seong $\mathrm{Ko}^{3 *}$ \\ ${ }^{1}$ Department of Business Administration, Kyungsung University \\ 309 Suyeong-ro, Nam-gu, Busan, 48434, South Korea \\ khchung@ks.ac.kr \\ ${ }^{2}$ Department of Industrial and Management Engineering, Korea University \\ 145 Anam-ro, Seongbuk-gu, Seoul, 02841, South Korea \\ rhtmddbs@korea.ac.kr \\ ${ }^{3}$ Department of Industrial and Management Engineering, Kyungsung University \\ 309 Suyeong-ro, Nam-gu, Busan, 48434, South Korea \\ csko@ks.ac.kr \\ * Corresponding author
}

\begin{abstract}
While the courier service demand has been continuously increasing over the last decade, the unit price has been dropping due to the more severe competition among the courier services. The courier service companies with low market share are making several types of efforts to survive in competitive market. Collaboration via the economy of sharing can allow the courier service companies to extend their service network and increase the market share. This study suggests a collaboration model to increase the competitiveness of every participating company. In addition, a nucleolus-based profit allocation method is applied for fair allocation of the profits to each participating company based on a cooperative game theory. An illustrative example problem demonstrates the applicability and efficiency of the proposed model.
\end{abstract}

Keywords: Courier Service, Economy of Sharing, Collaborative, Sustainable, Nucleolus

\section{Introduction}

In recent years, the concept for economy of sharing has been applied in various industry areas to meet the needs for utilizing the physical assets more efficiently. It could generate innovation-based community, and foster changes in business relationships up to the ecosystem. The consumer-driven sharing economy based on trust and experience such as Airbnb and Uber, etc. is gradually transferring to the emphasis on B2B (business-to-business) shared economic support for preventing duplicate asset loss. Compared with other industries transportation and logistics sector are leading the sharing economy. In particular, it has been active in the aviation and maritime transport and extended to several sectors of land transport. Nowadays, rapid increase in B2C(business-to-customer) is accelerating a steep surge of courier service market. The courier amount in Korean courier market has continuously been growing year by year. 
On the other hand, the unit price has been dropping due to the more severe competition among the courier service providers. In the end, the courier companies with low market share are not likely to survive in competitive market and cannot help avoiding collaboration for increasing their market shares company [1,2].

The objective of this study is to apply the sharing economy to the courier service for developing win-win business model and suggest an equitable allocation method of alliance profits based on co-operative game theory. A study for the courier service network design reflecting collaboration was first performed by Chung et al. [4]. Then some decision making models appeared considering several types of collaborations following it [5-10]. Also, Ko et al. carried out a collaboration-based reconfiguration problem with cut-off time adjustments in courier service network [13]. Ferdinand et al. took account of collaborative pick-up and courier routing problem of line-haul vehicles for maximizing the profits of participating companies [11]. Recently, Chung et al. [3] proposed a sustainable collaboration model with monopoly of service centers using Shapley value allocation. Their study was also extended to the problem of sharing consolidation terminals of each company [2]. A multi-objective non-linear integer programming model was developed for reflecting two types of collaboration problems such as survival of service centers and terminal sharing simultaneously.

\section{Model Design}

Suppose that there are $m$ express courier companies, and that the locations of terminals and service centers operated by each company are known in advance. And it is assumed that there are $n$ merging regions where companies have a relatively small delivery amount. In addition, suppose that the daily delivery amount of every company in each region and the processing capacity of terminals per day are given beforehand.

In order to develop the mathematical formulation for this problem some notations are introduced.

I : Set of express courier companies, $I=\{1,2, \ldots, m\}$

$J \quad$ : Set of service regions in which service centers are to be merged, $J=\{1,2, \ldots, n\}$

$T_{i} \quad$ : Set of consolidation terminals for company $i, i \in I$

$J_{i k} \quad$ : Set of merging regions allocated to company $i$ 's terminal $k, i \in I, k \in T_{i}$

$d_{i j}$ : Daily delivery amount of company $i$ within the merging region $j, i \in I, j \in J$

$D_{j} \quad$ : Sum of daily delivery amount of all the service centers within the merging region $j, j \in J$

$r_{i j}$ : Revenue that company $i$ obtains by delivering one unit within the merging region $j, i \in I, j \in J$

$c_{i j}^{1} \quad$ : Unit delivery cost when company $i$ 's service center exists in the merging region $j, i \in I, j \in J$

$c_{i j}^{2} \quad$ : Unit delivery cost when company $i$ 's service center does not exist in the merging region $j, i \in I, j \in J$

$a_{i j}$ : Indicator constant such that $a_{i j}=1$, if company $i$ 's service center exists in the merging region $j$ before alliance, $a_{i j}=0$, otherwise, $i \in I, j \in J$ 
$Q_{i k}$ : Delivery process capacity remaining at terminal $k$ of company $i, j \in J, k \in T_{j}$

$f_{i j}$ : Daily fixed cost for operating the service center when company $i$ 's service center exists in the merging region $j, i \in I, j \in J$

$x_{i j}$ : Binary variable such that $x_{i j}=1$, if company $i$ 's service center in the region $i$ is still open after alliance, $x_{i j}=0$ otherwise, $i \in I, j \in J$

The problem can be formulated as the following multi-objective integer programming model $(\mathrm{P})$ with $m$ objective functions:

(P)

$$
\begin{gathered}
\operatorname{Max} Z_{1}=\sum_{j \in J}\left(r_{1 j}-c_{1 j}^{1}\right) a_{1 j}\left(D_{j} x_{1 j}-d_{1 j}\right) \\
+\sum_{j \in J} f_{1 j} a_{1 j}\left(1-x_{1 j}\right)+\sum_{j \in J}\left(c_{1 j}^{2}-r_{1 j}\right) d_{1 j}\left(1-a_{1 j}\right) \\
\vdots \\
\operatorname{Max} Z_{m}=\sum_{j \in J}\left(r_{m j}-c_{m j}^{1}\right) a_{m j}\left(D_{j} x_{m j}-d_{m j}\right) \\
+\sum_{j \in J} f_{m j} a_{m j}\left(1-x_{m j}\right)+\sum_{j \in J}\left(c_{m j}^{2}-r_{m j}\right) d_{m j}\left(1-a_{m j}\right)
\end{gathered}
$$

Subject to

$$
\begin{array}{ll}
\sum_{i \in I} x_{i j}=1, & j \in J \\
x_{i j} \leq a_{i j}, & i \in I, j \in J \\
\sum_{j \in J}\left(D_{j} x_{i j}-d_{i j}\right) \leq Q_{i k}, & i \in I, k \in T_{i} \\
x_{i j} \in\{0,1\}, & i \in I, j \in J
\end{array}
$$

The objective function (1) consists of $m$ conflicting objectives corresponding to $m$ companies. Each objective function represents the sum of net profit increases obtained through alliance. Constraint (2) assures that only one service centers can be open in each merging region and all the others should be closed. Constraint (3) implies that open service center is chosen among the existing service centers in the merging region. Constraint (4) means that the sum of daily delivery amount of merging regions allocated to a terminal cannot exceed more than process capacity remaining at the terminal. Constraints (5) represents 0-1 integer variable.

\section{Nucleolus-based profit allocation procedure}

To sustain long-term collaboration, a fair allocation of coalition profit is very important. 
In cooperative game theory there exists a core for any coalition if completeness, rationality and marginality conditions are satisfied. Necessity of coalition is more emphasized by means of existence of the core. Since no core or too many cores for some coalitions may exist, Shapley value and Nucleolus-based allocations are suggested as a single solution procedure $[12,15]$. Shapley value is well known as the most equitable profit sharing method in cooperative game theory, which reflects a concept to distribute synergies obtained through the coalition according to the marginal contribution of participants [14]. However, its weakness is that it may not satisfy core conditions. On the contrary, nucleolus-based allocation is proposed to overcome the problem of Shapley value. It tries to maximize excess vector under the core conditions. To find a nucleolus-based allocation for combinations of three companies' coalitions the linear programming is developed as follows:

Maximize $t$

Subject to

$$
\begin{aligned}
& R_{1} \geq C_{1}+t \\
& R_{2} \geq C_{2}+t \\
& R_{3} \geq C_{3}+t \\
& R_{1}+R_{2} \geq C_{12}+t \\
& R_{1}+R_{3} \geq C_{13}+t \\
& R_{2}+R_{3} \geq C_{23}+t \\
& R_{1}+R_{2}+R_{3}=C_{123} \\
& R_{1}, R_{2}, R_{3}, \mathrm{t} \geq 0
\end{aligned}
$$

where $t$ is excess vector, $R_{i}$ is profit allocation for company $i, C_{i}, C_{i j}, C_{i j k}$ means coalition profit for only company $i$, companies $i$ and $j$, companies $i, j$ and $k$, respectively.

The objective function (6) means maximum of excess vector. Constraints (7)-(12) assure satisfaction of rationality and marginality conditions of the core. Constraint (13) means core's completeness. Constraint (14) represents non-negativity.

\section{$4 \quad$ Numerical Example}

An illustrative example is provided to explain the appropriateness of the collaboration model and to evaluate the nucleolus-based allocation. It is assumed that there are three companies with two consolidation terminals and ten merging regions. Table 1 shows delivery amount, allocated terminal, and capital recovery from fixed assets according to service center closedown for each company A, B and C. Current remaining processing capacities of terminal for each companies are generated as shown in Table 2. 
Table 1. Data for company A, B, and C

\begin{tabular}{c||c|c|c|c|c|c|c|c|c}
\hline \multicolumn{1}{c||}{$\begin{array}{c}\text { Regions of } \\
\text { Service Centers }\end{array}$} & \multicolumn{3}{c|}{ Delivery Amount } & \multicolumn{3}{c|}{ Allocated Terminal } & \multicolumn{3}{c}{ Daily fixed cost (\$) } \\
\cline { 2 - 11 } & A & B & C & A & B & C & A & B & C \\
\hline \hline 1 & 29 & 45 & 37 & 1 & 1 & 2 & 77 & 91 & 89 \\
\hline 2 & 22 & 17 & 29 & 1 & 2 & 2 & 97 & 79 & 79 \\
\hline 3 & 46 & 30 & 40 & 1 & 2 & 2 & 89 & 67 & 83 \\
\hline 4 & 10 & 26 & 27 & 2 & 2 & 2 & 81 & 86 & 61 \\
\hline 5 & 48 & 42 & 19 & 2 & 1 & 1 & 66 & 54 & - \\
\hline 6 & 47 & 42 & 35 & 1 & 2 & 1 & 64 & 62 & - \\
\hline 7 & 29 & 14 & 37 & 2 & 2 & 2 & 67 & - & 94 \\
\hline 8 & 25 & 18 & 23 & 1 & 1 & 2 & 82 & - & 63 \\
\hline 9 & 20 & 36 & 29 & 2 & 1 & 1 & - & 77 & 90 \\
\hline 10 & 23 & 50 & 42 & 2 & 2 & 1 & - & 80 & 52 \\
\hline
\end{tabular}

Table 2. Data for each company's remaining processing capacity

\begin{tabular}{c|c|c|c|c|c}
\hline$Q_{A 1}^{1}$ & $Q_{A 2}^{1}$ & $Q_{B 1}^{1}$ & $Q_{B 2}^{1}$ & $Q_{C 1}^{1}$ & $Q_{C 2}^{1}$ \\
\hline \hline 145 & 137 & 112 & 162 & 129 & 106 \\
\hline
\end{tabular}

Table 3. Optimal solution for maxmin criterion

\begin{tabular}{c||c|c|c|c|c|c|c|c|c|c}
\hline & 1 & 2 & 3 & 4 & 5 & 6 & 7 & 8 & 9 & 10 \\
\hline \hline$x_{A j}$ & 1 & 1 & 0 & 0 & 1 & 0 & 1 & 0 & 0 & 0 \\
\hline$x_{B j}$ & 0 & 0 & 1 & 0 & 0 & 1 & 0 & 0 & 1 & 0 \\
\hline$x_{C j}$ & 0 & 0 & 0 & 1 & 0 & 0 & 0 & 1 & 0 & 1 \\
\hline
\end{tabular}

Table 4. Optimal solution for maxsum criterion

\begin{tabular}{c||c|c|c|c|c|c|c|c|c|c}
\hline & 1 & 2 & 3 & 4 & 5 & 6 & 7 & 8 & 9 & 10 \\
\hline \hline$x_{A j}$ & 1 & 0 & 0 & 0 & 0 & 0 & 1 & 0 & 0 & 0 \\
\hline$x_{B j}$ & 0 & 1 & 1 & 0 & 1 & 1 & 0 & 0 & 1 & 0 \\
\hline$x_{C j}$ & 0 & 0 & 0 & 1 & 0 & 0 & 0 & 1 & 0 & 1 \\
\hline
\end{tabular}


Table 5. Nucleolus-based and Shapley value allocation

\begin{tabular}{|c|c|c|c|c|c|}
\hline \multirow{2}{*}{\multicolumn{2}{|c|}{ Subgroup }} & \multirow{3}{*}{$\begin{array}{c}\begin{array}{c}\text { Subgroup } \\
\text { output }\end{array} \\
0\end{array}$} & \multicolumn{3}{|c|}{ Marginal contribution } \\
\hline & & & \multirow{2}{*}{$\begin{array}{l}\mathrm{A} \\
0\end{array}$} & \multirow[t]{2}{*}{$\mathrm{B}$} & \multirow[t]{2}{*}{$\mathrm{C}$} \\
\hline \multirow{4}{*}{$\begin{array}{c}\text { No } \\
\text { collaboration }\end{array}$} & $\mathrm{A}$ & & & & \\
\hline & $\mathrm{B}$ & 0 & & 0 & \\
\hline & $\mathrm{C}$ & 0 & & & 0 \\
\hline & \multicolumn{2}{|c|}{ Column Average((1)) } & 0 & 0 & 0 \\
\hline \multirow{4}{*}{$\begin{array}{l}\text { Collaboration } \\
\text { between two } \\
\text { companies }\end{array}$} & $A, B$ & 606 & 606 & 606 & \\
\hline & $\mathrm{B}, \mathrm{C}$ & 638 & & 638 & 638 \\
\hline & $\mathrm{A}, \mathrm{C}$ & 678 & 678 & & 678 \\
\hline & \multicolumn{2}{|c|}{ Column Average((2)) } & 642 & 622 & 658 \\
\hline Full collaboration & $\mathrm{A}, \mathrm{B}, \mathrm{C}(\mathrm{3})$ & 1,365 & 727 & 687 & 759 \\
\hline \multicolumn{3}{|c|}{ Shapley Value } & 456.3 & 436.3 & 472.3 \\
\hline \multicolumn{3}{|c|}{ Nucleolus } & 457.3 & 417.3 & 489.8 \\
\hline
\end{tabular}

The optimal solution for maxmin criterion can be obtained using Excel Solver in Table 3. The total profit obtained from strategic alliance by consolidating the service centers is $\$ 1,345$. On the other hand, the optimal solution acquired by the maxsum criterion is shown in Table 4, and the total profit that is shown in this table is $\$ 1,365$, which is greater than the total profit by the maxmin criterion. Table 5 also shows the Shapley value results by applying maxsum criterion and an allocation method by fairly allocating to each company based on its marginal contribution. According to Tarashev et al. [16] the marginal contribution of a company to a subgroup is calculated as the output of the subgroup minus the output of the same subgroup excluding the individual participant. Then the Shapley value of each company is the average of its marginal contributions across all differently sized subgroups. On the contrary, the linear programming was solved with the parameter values; $C_{1}=0, C_{2}=0, C_{3}=0, C_{12}=606$, $\mathrm{C}_{13}=678, \mathrm{C}_{23}=638$ and $\mathrm{C}_{123}=1,365$ to find the nucleolus-based allocation for three companies. By seeking benefits based on the maxmin criterion, all participating companies will feel fair and impartial. However, applying the maxsum criterion increases the total benefit through coalition compared to the maxmin criterion. Therefore, it is better to apply the maxsum criterion from the perspective of total benefit. But, there exists still a problem of how to distribute coalition profits to affiliates. Using Shapley value or nucleolus concept can be a good alternative because it can be rationally distributed.

\section{Conclusions}

Most small and medium-sized courier service companies in Korea are in trouble due to severe competition in the market. Coalition is emerging as a unique survival strategy to obtain a higher market share with limited resources in industry fields. In addition, one 
of the difficult parts of applying collaboration is determining how to allocate costs or profits to each participating company. This study proposed a decision making model for alliance in courier services. A nucleolus-based allocation as a systematic allocation methodology was also proposed for fair allocation to each company. This study can accelerate the collaboration in several industry sectors by providing technology for coalition and fair allocation for its sustainability. Furthermore, in further research, various types of collaboration models related to the overall network design in express delivery services will also be included.

Acknowledgments. This research was supported by Basic Science Research Program though the National Research Foundation of Korea (NRF) funded by the Ministry of Education, Science and Technology (NRF-2015R1D1A3A01019761).

\section{References}

1. Bae, M.S.: Korean Delivery Service Market. National Logistics Information Center Bulletin, Seoul (2017).

2. Chung, K.H., Ko, S.Y., Ko, C.S.: A Cooperative Game-Theoretic Network Design for Collaborative Operation of Service Centers and Consolidation Terminals in Express Delivery Services. International Journal of Industrial Engineering 25(1), 18-28 (2018).

3. Chung, K.H., Ko, S.Y., Lee, C.U., Ko, C.S.: Sustainable Collaboration Model with Monopoly of Service Centers in Express Delivery Services Based on Shapley Value Allocation. International Journal of Industrial Engineering 23(3), 166-173 (2016).

4. Chung, K.H., Rho, J.J., Ko, C.S.: Strategic Alliance Model with Regional Monopoly of Service Centers in Express Courier Services. International Journal of Service and Operation Management 5(6), 774-786 (2009).

5. Chung, K.H., Ko, C.S., Hwang, Y.M., Rho, J.J.: Network Design for Strategic Alliance in Express Courier Services: A Fuzzy Set Approach. International Journal of Innovative Computing, Information and Control 6(1), 349-359 (2010).

6. Chung, K.H., Ko, H.J., Ferdinand, F.N., Ko, C.S.: A Fuzzy Set-Theoretic Approach to the Weak Strategic Alliance for The Survival of Multiple Service Centers in Express Courier Services. ICIC Express Letters: International Journal of Research and Surveys 5(2), 385-389 (2011).

7. Ferdinand, F.N., Chung, K.H., Ko, H.J., Ko, C.S.: Genetic Algorithm-Based Approach to Multi Objective Decision Making Model for Strategic Alliances In Express Courier Services. ICIC Express Letters: International Journal of Research and Surveys 6(4), 929-934 (2012(a)).

8. Ferdinand, F.N., Chung, K.H., Ko, H.J., Ko, C.S.: A Compromised Decision Making Model for Implementing a Strategic Alliance in Express Courier Services. INFORMATION: An International Interdisciplinary Journal 15(12c), 6173-6188 (2012(b)).

9. Ferdinand, F.N., Moon, I. K., Chung, K.H., Ko, C.S.: A Decision Making Model for Strategic Alliance-Based Network Design in Express Delivery Services. ICIC Express Letters: International Journal of Research and Surveys 7(6), 1813-1818 (2013).

10. Ferdinand, F.N., Chung, K.H., Lee,E.G., Ko, C.S.: Collaborative System Design in Express Delivery Services: Formulation and Solution Heuristic. ICIC Express Letters part B: Applications 5(1), 2185-2766 (2014(a)). 
11. Ferdinand, F.N., Kim, Y.J., Lee, H.K., Ko, C.S.: A Study on Collaborative Pick-up and Delivery Routing Problem of Line-haul Vehicles in Express Delivery Services. International Journal of Industrial Engineering 21(6), 376-383 (2014(b)).

12. Kimms, A., Cetiner, D.: Approximate Nucleolus-based Revenue Sharing in Airline Alliances. European Journal of Operational Research 220(2), 510-521 (2012).

13. Ko, C.S., Chung, K.H., Ferdinand, F.N., Ko, H.J.: Collaboration Based Reconfiguration of a Package Service Network with Multiple Consolidation Terminal. International Journal of Industrial Engineering 20(1-2), 72-83 (2013).

14. Shapley, L.: A Value for n-Person Games, Annals of Mathematical Studies. 28, 307-317 (1953).

15. Schmeidler, D.: The Nucleolus of a Characteristic Function Game. SIAM Journal of Applied Mathematics. 17(6), 1163-1170 (1969).

16. Tarashev, N., Borio, C., Tsatsaronis, K.: The Systemic Importance of Financial Institutions. BIS Quarterly Review, 75-87 (2009). 